\title{
Possible Linkage between $X g$ and the Locus for a Gene causing Mental Retardation with or without Hydrocephalus
}

\author{
K. FRIED* and RUTH SANGER \\ From the University Department of Human Genetics, Western General Hospital, Edinburgh and the MRC \\ Blood Group Unit, The Lister Institute, London
}

Summary. The Xg groups of a kindred in which an X-borne gene evidently caused mental retardation with or without hydrocephalus suggest that the locus for this gene may be linked to $X g$.

Hereditary hydrocephalus (Bickers and Adams, 1949 ) is now known, at least in some families, to be an X-borne condition (Edwards, 1961).

A few families with the X-borne type of hydrocephalus have been tested for the $\mathrm{Xg}$ blood groups but with no hint of linkage between their two loci (Edwards, 1968; Jabbour, 1968).

In a kindred recently reported by Fried (1972) a single X-borne gene has apparently caused mental retardation sometimes with and sometimes without hydrocephalus. The $\mathrm{Xg}$ groups of the family (Fig. 1) pose a difficult exercise in scoring for linkage.

The deceased maternal grandparents, I.1 and I.2, of the propositus could have had one of three arrangements of $\mathrm{Xg}$ genotypes.

1. $X g^{a} X g^{a} \times X g$. From the groups of the family this is the most likely guess and the linkage information would then be:

Generation II, no score

Generation III, 9 non-recombinants: 1 recombinant

for which the lod scores for the various recombination fractions would be:

$\begin{array}{llllllllll}0.00 & 0.05 & 0.1 & 0.15 & 0.2 & 0.25 & 0.3 & 0.35 & 0.4 & 0.45\end{array}$

$\begin{array}{llllllllll}-\infty & 1.511 & 1.596 & 1.547 & 1.438 & 1.283 & 1.092 & 0.871 & 0.614 & 0.323\end{array}$

Received 24 August 1972

* Present address: Department of Human Genetics, Tel Aviv University, Tel Aviv, Israel. and very suggestive of linkage with a most likely recombination fraction of $0 \cdot 11$.

2. $X g^{a} X g \times X g^{a}$. This we calculate to be about 15 times less likely than arrangement 1 , but cannot be disregarded. The linkage information would now become:

Generation II, $z_{1}$ 6:0

Generation III, 1 non-recombinant: 8 recombinants

and the evidence, though notably conflicting between the two generations, would, in the sum, be strongly against linkage.

3. $X g^{a} X g \times X g$. This is the least likely arrangement, for the probability of finding all eight daughters and sons in generation II to be $\mathrm{Xg}(\mathrm{a}+)$ would be only 1 in 256 . However, the score (excluding II.2 who may or may not be a carrier) would be:

Generation II, $z_{1} 6: 1$

Generation III, 9 non-recombinants: 1 recombinant

and again very suggestive of linkage.

Professor G. R. Fraser and Professor J. H. Edwards kindly gave a great deal of thought to presenting all the possible arrangements in this family to the assessment of the computer: the outcome (Fig. 2) was in favour of linkage between the disease locus and $X g$ with a maximum likelihood of $20 \cdot 2$ at a recombination fraction of $0 \cdot 11$. 


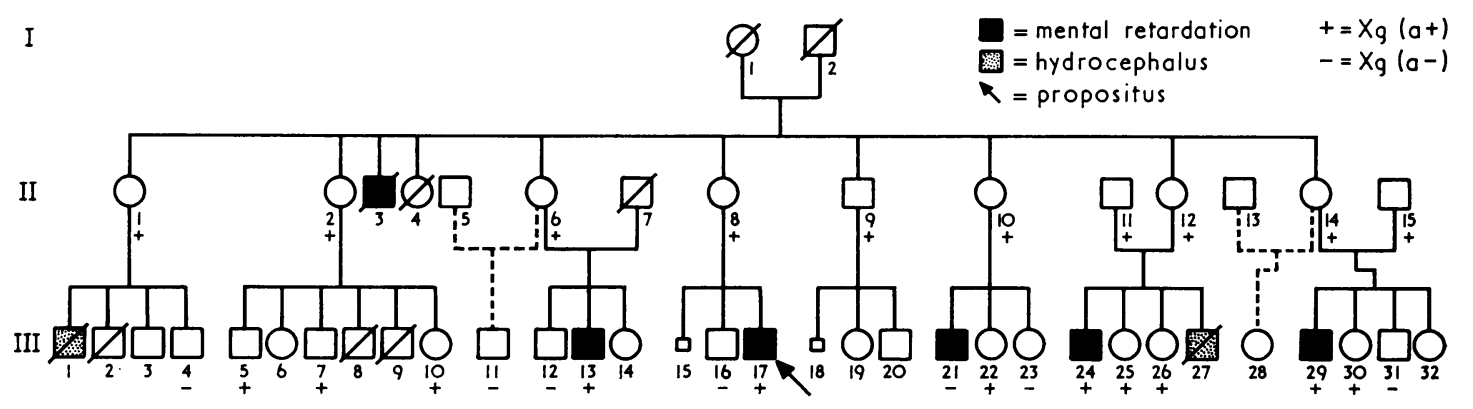

FIG. 1. The Xg groups of the family.

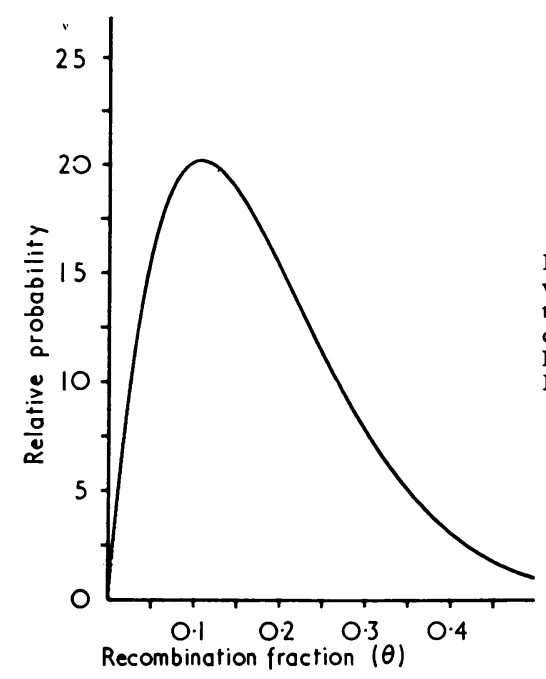

REFERENCES

Bickers, D. S. and Adams, R. D. (1949). Hereditary stenosis of the aqueduct of Sylvius as a cause of congenital hydrocephalus. Brain, 72, 246-262.

Edwards, J. H. (1961). The syndrome of sex-linked hydrocephalus. Archives of Disease in Childhood, 36, 486-493.
FIG. 2. Relative probabilities of linkage for various values of the recombination fraction between the locus for this form of mental retardation and $\mathrm{Xg}$. (With acknowledgment to Professor G. R. Fraser and Professor J. H. Edwards.)
Edwards, J. H. (1968). Cited by Race, R. R. and Sanger, R. In Blood Groups in Man, 5th edition, p. 545. Blackwell, Oxford.

Fried, K. (1972). X-linked mental retardation and/or hydrocephalus. Clinical Genetics, 3, 258-263.

Jabbour, J. T. (1968). Cited by Race, R. R. and Sanger, R. In Blood Groups in Man, 5th edition, p. 545. Blackwell, Oxford. 